\title{
Building Up an Ecologically Sustainable Society by Inculcating Environmental Ethics and Values in Children
}

\author{
Dr. Saba Siddiqui, Dr. Zeba Aqil \\ Assistant Professor Faculty of Education, Integral University, Lucknow. \\ Associate Professor Faculty of Education, Integral University, Lucknow.
}

\begin{abstract}
Ecological sustainable society is a relevant concern of the people of today and tomorrow. A Chinese Proverb says "If you are thinking a year ahead, plant a seed, if you are thinking decade ahead plant a tree and if you are thinking a century ahead educate people". The role of education in environment protection was recognized in the 1980. In 1988 UNESCO put toward the plan 'education for sustainability'. Early childhood education for sustainability, an emerging national and international field launched 'the United Nations decade of education for sustainable development (2005-2014)' UNESCO, 2005. They are obtaining good results in creating consciousness.

The realistic angle of environmental problem will only be met if it is rooted in the local concrete reality of young children. In the childhood period, children develop their basic values, attitudes, skills, behavior and habits which may be long lasting. Experiences during this phase extensively influence physical \& neurological development which drivebiological, psychological and social response throughout the entire life span. They can be initiators provocateurs, researchers and environmental activist.

Childhood has the potential to foster values that support sustainable development. Children are the part of society who will bear the consequences of our actions and inactions on sustainability related lesson.

"I am myself and my circumstances" said a Spanish philosopher.Children being a part of society, problems of social, cultural and physical environment in which is inserted a part of them, effects them. Children live in the world confronted by mounting environmental problems like global deforestation, loss of species diversity, pollution, global warming and so on. So it is the duty of adults to tap them and bring up a tactful environmental friendly future citizens.

The inculcation of environmental ethics can be done formally and informally. The compulsory school presents a continuous evolution while informal, family environmental values always seep in off and on.

The ethics of respecting nature, understanding nature, exploring nature, respect of individual cultural difference, learning diversity should be promoted in early childhood. Humans are not the hosts. Human beings and nature should get along harmoniously and to develop that it is necessary to reinforce protection, and this has to be understood as soon as the child starts understanding nature and other important values.
\end{abstract}

\section{Introduction}

The world is not left to us by our parents. It is lent to us by our children. (African Proverb)

Global warming and globalization are challenging the world at a speed and magnitude that call for a global effort to develop a more sustainable world. We must begin with the early childhood. Investing in early childhood and building a sustainable society are strongly related. Sustainable development is a concept that emerged in the 1980s. Sustainable development is the development that meets the needs of the present without compromising the ability of future generation to meet their own need. The idea of sustainable society does not mean to maintain status quo ad infinitum into the future or about sustaining the damage. It is about reconfiguring society within the limits of the earth so that over a time society will be even more able to realize and instantiate what is good and valuable (Melissa lane, 2011).The crisis is a major threat and therefore ecological education is indispensible. Childhood is the period with enormous potential in fostering values, attitudes, skills and behaviors. If the environmental values are taught in childhood and environmental ethics are inculcated, the seasoned citizens will come up to whom the planet can be fearlessly handed over. Awareness and grooming in the early childhood can transform them significantly. United Nations has already recommended the role of environmental education in children. We need to focus on implementing it. However in our present world with growing challenges and economic and social crisis giving all children good conditions to develop and learn is problematic, especially in developing countries where over 200 million children under five years are not fulfilling their developmental potential(Lanced Series, 2007). The problems, facing the world during the life times of children currently in early childhood programmes, have arisen because of choices, actions and life styles of well meaning people, such as the teachers and parents. If young children are to adopt sustainable life styles in the future, they need to understand how their lives are linked to, and effect nature, and prefer to make 
wise and responsible choices about what they eat, how they travel, what they wear and relate to people in their local community and in distant lands. This generation could make or break the earth's future (Tricia Herbert, 2008).Childhood is the ideal time for the inculcation of environmental ethics so that they grow up into environmental sensitive adults.

The founder of early childhood, Friedrich Froebel, began the first kindergarten-literally children's garden - in the nineteenth century. These kindergarten had individual gardens for each child, enclosed by a communal garden. Children used their garden as they wished for play and experimenting - gaining first hand experiment. Froebel believed that children should grow in harmony with nature. Other pioneers of early childhood education, shared Froebel's emphasis on the connection between young children and nature. When it comes to the problems of nature, they should be taught to deal with it at an early stage.

\section{Quality Education in Early Childhood: A foundation of Sustainable Society}

"Education is the most powerful weapon which you can use to change the world"

Nelson Mandela

Education is humanity's best hope and most effective means in the quest to achieve sustainable development (1997 UNESCO Report, Education for a sustainable future). To protect our ecological system, to make right choices and to protect future generations of humans and other living species, we not only need economic, technological and administrative measures but to provide ecological and environmental knowledge to the students. Children need to learn that, ecological problems go beyond national boundaries and call for new ways of collaboration, partnership and ways of learning (Martin and Jucker, 2005). Education is the best means to introduce them with values, importance and ethics related to environment.

"The greatest gift we can give our children is to assist them in their dreams of a planet of pure air, water, sun light and soil where the community of all living beings can flourish in the celebration of existence".

Thomas Berry

The values taught today will become a habit tomorrow. Educational conditions should be created to assist children in developing the child cognitively, physically, spiritually and ethically. The existence of human beings as well as other live forms depends on individual developing the knowledge and awareness and educating for sustainability (Dunlap, Vanliene, Mertig and Jones2000).

Importance of education in society is indispensible and cohering, which is why society and knowledge cannot be separated. Education can be used as the tool for reaching the specific target of building up an ecological sustainable society. Education related to environment can help us to understand the surroundings in a better way, the threats and our potentials to face it. of Action)

Quality early education is necessary for the benefits of early learning to continue. (Dakar Framework

\section{Instilling environmental ethics formally and informally -}

Education starts in the mother's lap. Families are the child's first educator. They shape the child's attitude and skill. Learning can be undertaken by parents, siblings, grandparents and extended family members. Children are the observers and followers. The ethics followed in a family silently seeps in.

"Keep in mind always the present you are constructing. It should be the future you want"

Walker

The community is also responsible for development of values. Different community programmes can bring about marked difference in approach towards environment. These community programmes provide people the opportunities to become an effective agent of bringing about sustainable development and tapping the same in the children. The values of compassion and respect developed in the childhood can bring up eco intelligent and eco sensitive adults.

Sustainable development requires an ethos of compassion, respect for difference (Chan 2006). The role of formal education at play schools cannot be denied. Compulsory school presents continuous evolution. It is important to keep in mind that the social representation of childhood, family and early childhood education presented in the teachers, parents and decision makers universe come from a preexistent referential of thinking that were generated in locales of common sense and have been evocated for a long time, therefore difficult to be negotiated (Moscovici 2005). Conscious of the need for continuity in children's education, starting strong (OECD 2001) made a number of recommendations to promote a strong and equal partnership between early childhood education and primary school. Traditional schools should understand the difference between the traditional education and education for sustainable development. 


\begin{tabular}{|l|l|}
\hline Traditional Education & Education for sustainable development \\
\hline $\begin{array}{l}\text { Practical and theoretical learning for basic survival and } \\
\text { synergy with various aspects of development. }\end{array}$ & $\begin{array}{l}\text { Basic education that focuses on imparting knowledge skills, values } \\
\text { and perspectives that lead to supporting people to lead sustainable } \\
\text { lives. }\end{array}$ \\
\hline $\begin{array}{l}\text { Value based learning with emphasis on principles of } \\
\text { sustainability in all spheres of life. }\end{array}$ & $\begin{array}{l}\text { Includes principles, skills, perspectives and values related to } \\
\text { sustainability in social, environmental, and economic realms for } \\
\text { lifelong learning. }\end{array}$ \\
\hline $\begin{array}{l}\text { Transmission of information on matters of concern to } \\
\text { communities through council meetings and role play etc. }\end{array}$ & Informed citizens and knowledgeable communities. \\
\hline $\begin{array}{l}\text { Apprenticeship to enhance knowledge and skills in different } \\
\text { professions. }\end{array}$ & $\begin{array}{l}\text { Training all sectors of the work force to impart knowledge and skills } \\
\text { necessary to perform work in a sustainable manner. }\end{array}$ \\
\hline $\begin{array}{l}\text { Strong roots in indigenous knowledge systems, tried and } \\
\text { tested over time and dynamic to incorporate emerging issues. }\end{array}$ & $\begin{array}{l}\text { Meet diverse, social, economic and environmental conditions in } \\
\text { relevant and culturally appropriate ways, taking into account } \\
\text { indigenous cultures and knowledge systems. }\end{array}$ \\
\hline
\end{tabular}

Source: Lorraine Otieno, 2007

Therefore, early learning for environmental ethics has to take place in different settings, in families, communities, schools, early childhood programmes to name a few. Formal non formal and informal settings should all be used.

\section{Promoting environmental ethics in early childhood -}

Early childhood is defined as the years from birth to six. From birth, young children develop socially, emotionally, cognitively and physically acquiring the knowledge, skills and attitudes essential to their ongoing development and adult life. It is the period when they develop their basic values and behavior that becomes permanent later.Early childhood education is about laying a sound intellectual, psychological, emotional, social and physical foundation for development and lifelong learning.

A synthesis of early childhood education and education for sustainability is finally beginning to emerge as an active new field of interest. The first international meeting dedicated to the role of early childhood education and sustainability was held in Sweden, in May 2007, a UNESCO supported event, that brought together people from all continents of the globe. The values and ethics liker wise use of resources, cultural diversities, gender equality and democracy can be fostered in this period. The importance of starting this education as early as possible is strongly felt, but it cannot be dealt with in abstraction - it needs to be rooted in the local concrete reality of young children if it is to have real meaning and impact. The values built in early years are the strong and permanent roots for the entire life. The unforgettable moment of infancy is remembered by everyone with pleasure.

'I am myself and my circumstances' said the Spanish philosopher Ortega Y Gasset. It means the dreams, desires, necessities, language, problems of social cultural nature etc hovers each and every individual of every age group. Nothing that surrounds them is strange to them. Problems like global warming, ozone depletion and pollution cannot be a strange and new concept to children. Hart (1997) insists that even very young children have the capacity for active participation and acquisition of political literacy skills. Though it is critical, that children are not seen as the 'redemptive' vehicle (Dalberg and Petrie, 2002) where the social ills of the world are cured through children. We must overcome challenges not for our children but with our children.

Early education can be facilitated by providing

- Opportunity to participate in many varied learning experiences integrating many knowledge areas.

- Opportunity to observe changes in an environment overtime.

- Opportunity to play a valued part in real life activity (e.g. gardening, cooking, building etc)

- Opportunity to use real tools and begin to develop practical skills

- Encouragement of a sense of wonder about the natural world.

Source: Tricia Herbert

The researcher suggests that many projects can be embedded in childhood activities. Children love nature and become keen observers of their surroundings. They explore different natural phenomenon. They explore how a seed comes out of a fruit and again gives birth to a new sapling. They also observe, how nature takes care of its rubbish through the cycle of decomposing and reusing material. The cultivation of vegetables itself teaches the importance and gifts of nature. Nursing of animals can make them sensitive to other species. The sustainable planet project can be undertaken according to children's own particular environmental interest as identified in the diagram below. 


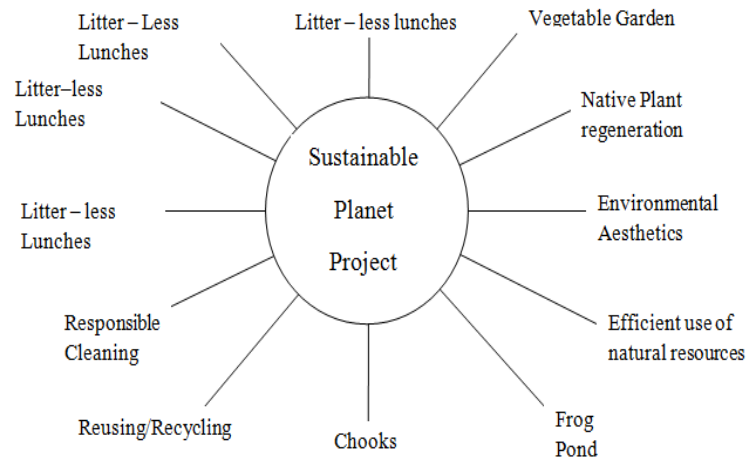

Sustainability ethic can be developed where thinking and acting sustainably permeates deep into the culture. This is also an ethics that supports the view that even very young children can critically respond to environmental and can be proactive participants in educational and environmental decision making - as initiators, provocateurs, researchers and environmental activist (Julie. M. Davis, 2008).Learning to enjoy and love nature is considered one of the premises for motivating people to preserve nature (Fisman, 2001; White, 2004)

Children everywhere are taught to respect other people and other cultures. Respecting environment is just its extension and in order to gain respect for nature, they need to experience its beauty and diversity and have the opportunity to become familiar with it.

\section{As you sow, so shall you reap}

If we act now to make "education for a sustainable future" a reality, future generations will inherit a healthy planet. The ethics developed in childhood becomes a permanent habit later. It has been found that if the ethics are activated in early years they are acquired in the middle years and later the adults apply them in different walks of life.

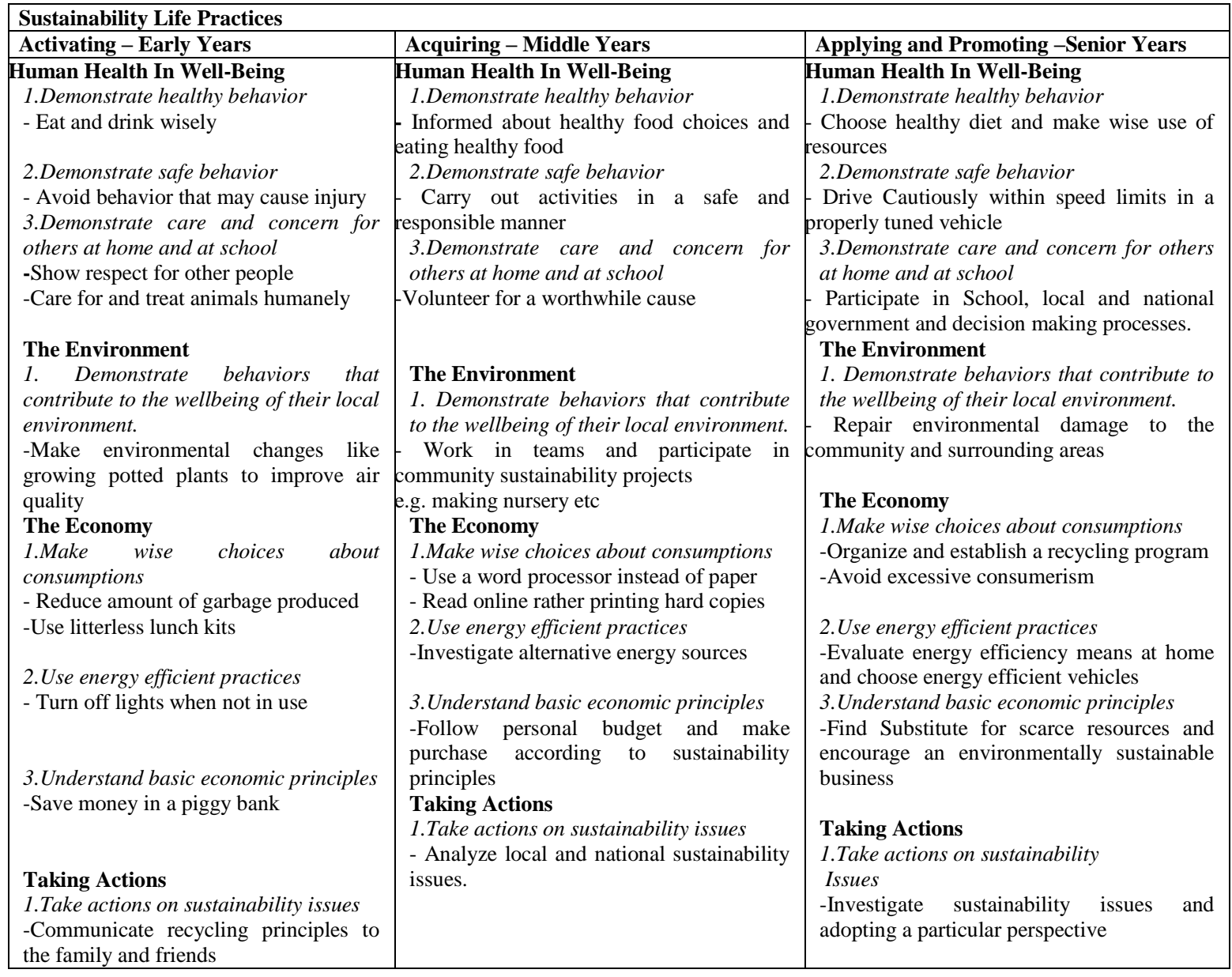


The above table reflects that the seeds of different environmental ethics are fruitful in the coming years. It is made clear in the above table that how a particular value taught in childhood becomes an integral part of personality. We are looking forward for the adults with these indigenous qualities. Education can facilitate these changes. Students need to know what to aim for in their future and to understand that they have the personal power to make a difference and effect change (Manitoba Education and Training, 2000).

\section{Conclusion}

The researcher infers that there can be no sustainability without a quality early childhood education. It is consistently proven that access to high quality early childhood education can have a positive impact on children. Efforts should be made to introduce different devices and methods for reaching the objective of sustainable development. The relevance of beginning in early years, the environmental ethical values along with moral values cannot be negated. Learning resources made from natural materials contribute to sustainability because they are economical and readily available. However there is a need for a conscious effort and decisions about the educational programmes. Reforms are needed in our curriculum to implement these values in our children. Our actions today, will determine the world of our children tomorrow. Childhood is the ideal time to mould the individuals and bring out the best of environmental values and ethics in them, if we do not invest in sustainability now, our children will necessarily pay a far greater price, both financially and in the quality of their lives.

\section{References}

[1] Chan, L.H. 2006. Re-orientating Teacher Education for Socially Sustainable Development. Paper Presented at the UNESCO Expert Meeting on Education for Sustainable Development, Bangkok, 1-3 May.

[2] Dakar Framework for Action: Education for All: Meeting our Collective Commitments.2000. Adopted by the World Education Forum, Dakar, Senegal, 26-28 April 2000. UNESCO. http://www.unesco.org/education/wef/en-conf/dakframeng.shtm

[3] Dalberg, P.; Petrie, P.2002. From Children's Services To Children's Spaces: Public Policy, Children and Childhood. New York: RoutledgeFalmer

[4] Davis, J (2008) What might education for sustainability look like in early childhood. A report to UNESCO

[5] Dunlap, R., Van Liere, K., Mertig, A., \& Jones, R.E. (2000). Measuring endorsement of the New Ecological Paradigm: A revised NEP scale. Journal of Social Issues, 56, 425-442.

[6] Fisman, L.2001. Child's Play: An Empirical Study of the Relationship between the Physical Form of Schoolyards and Children's Behavior. MESc 2001. Retrieved 18 February 2006 from Yale University, Yale School of Forestry and Environmental Studies. Web site: http://www.yale.edu/hixon/research/pdf/LFisman Playgrounds.pdf

[7] Hart, R. 1997. Children's Participation: The Theory and Practice of Involving Young Citizens in Community Development and Environmental Care. New York: UNICEF

[8] Lancet Series. 2007. Child Development in Developing Countries. January.

[9] Lorraine Otieno (2008) Cultural considerations in early childhood for sustainable development. Report to UNESCO

[10] Manitoba Education and training (2000) Education for a sustainable future: A resource for curriculum developers teachers and administrators.

[11] Martin, S., Jucker, R.(2005) Educating earth- literate leaders, Journal of Geography in Higher Education ,29(1),pp.19-30

[12] Melisa Lane (PEI) Eco Republic: What the ancients teach us about ethics virtue and sustainable living.

[13] Moscovici, S. 2005. Representacoessociais: investigacoesempsicologiasocial. [Social representations:Investigations in Social Psychology.] $3^{\text {rd }}$ ed. Petropolis (RJ), Vozes.

[14] OECD.2001.Starting Strong: Early Childhood Education and Care. Paris: Education and Training Division, OECD

[15] Tricia Herbert (2008) Eco intelligent education for a sustainable future life. International workshop, the role of early childhood education for a sustainable society. Goteborg Sweden

[16] UNESCO 1997 Educating for a sustainable future. Transdisciplinary vision for concerted action.

[17] White, R.2004. Interaction with Nature during the Middle Years: Its importance in Children's Development \& Nature's Future. Retrieved 29 November 2004 from: http://www.whitehutchinson.com/children/articles/nature.shtml. 